\title{
Kontribusi Usaha Ternak Sapi Perah Terhadap Pendapatan Keluarga Peternak di Kecamatan Musuk Kabupaten Boyolali
}

\author{
S. H. Purnomo*, E. T. Rahayu dan A. A. Setyawan \\ Prodi Peternakan, Fakultas Pertanian, Universitas Sebelas Maret \\ Jl. Ir. Sutami 36 A Ketigan Surakarta \\ E-mail: sutrisnohadi@staff.uns.ac.id
}

\begin{abstract}
ABSTRAK
Penelitian ini bertujuan untuk mengetahui karakteristik dan tatalaksana usaha ternak sapi perah, menganalisis besarnya kontribusi usaha ternak sapi perah terhadap pendapatan keluarga peternak, menganalisis hubungan antara skala usaha peternakan sapi perah dengan pendapatan dan kontribusi pendapatan usaha ternak sapi perah, menganalisis pengaruh berbagai faktor produksi terhadap tingkat pendapatan peternak. Penelitian ini dilaksanakan di Desa Ringin larik, Desa Kebon gulo dan Desa Dragan Kecamatan Musuk Kabupaten Boyolali pada bulan Juli 2013. Metode yang digunakan adalah Rapid Rural Appraisal (RRA). Jumlah sampel 60 responden. Data yang diperoleh meliputi data primer dari wawancara responden dan data sekunder diperoleh dari instansi yang terkait di Kabupaten Boyolali. Analisis data yang digunakan adalah analisis deskriptif, analisis pendapatan usaha ternak sapi perah, analisis pendapatan rumah tangga peternak, analisis kontribusi pendapatan usaha ternak sapi perah terhadap pendapatan rumah tangga peternak, analisis kolerasi pearson dan analisis regresi linier berganda. Hasil penelitian menunjukan rata-rata pendapatan bersih dari usaha ternak sapi perah skala 4 ekor per tahun adalah Rp. 6.483.050,33. Kontribusi usaha ternak sapi perah terhadap pendapatan rumah tangga peternak adalah 19,38 \%. Nilai korelasi antara skala usaha ternak sapi perah dengan pendapatan dan kontribusi pendapatan usaha ternak sapi perah memiliki nilai positif yaitu 0,597 dan 0,521. Nilai positif menunjukkan bahwa semakin besar skala usaha ternak sapi perah akan meningkatkan pendapatan peternak serta memiliki hubungan yang kuat. Hasil uji t pada analisis regresi, nilai koefisien $t_{\text {hitung }}$ variabel biaya tenaga kerja $\left(X_{3}\right)$ dan biaya IB $\left(X_{5}\right)$ yaitu 2,081 dan 2,066 lebih besar dari nilai $t_{\text {tabel }}$ atau signifikan.
\end{abstract}

Kata kunci: Keluarga peternak, kontribusi usaha, pendapatan, sapi perah

\section{Contribution of Business Dairy Cattle Farms to Income Family Farmers at District Musuk of Boyolali Regency}

The purpose of this study was to determine the characteristics and management of dairy cattle business, analyze the contribution of dairy cattle business to the family income of farmers, analyze the relationship between business income dairy cattle farm and revenue contribution of dairy cattle, analyze the influence of various factors on the level of production the income of farmers. This research was conducted in the Ringin larik village, Kebun Gulo and Dragan at District Musuk of Boyolali Regency in July 2013. The method is Rapid Rural Appraisal (RRA). Total of sample of 60 respondents. The data is primary data from interviews of respondents and secondary data obtained from relevant agencies in the district boyolali. Analysis of the data used is descriptive analysis, analysis of revenue dairy farmers, ranchers analysis of household income, revenue contribution analysis of dairy cattle ranchers on household income, pearson correlation analysis and multiple linear regression analysis. The results showed an average responden net income of the business dairy cattle 4 scale is Rp. 6,483,050.33 in year. The contribution of business dairy cattle breeders to household income is $19,38 \%$. The correlation of value between the scale of the dairy cattle business with revenues and contribution of dairy cattle income has a positive value is 0,597 and 0,521. Positive values indicate that larger scale dairy cattle business will increase farmers income and have a strong relationship. The results of the t test on regression analysis, coefficient of thitung variable labor costs (X3) and the cost of IB (X5) is 2,081 and 2,066 greater or significant t tabel.

Keywords: Contribution, dairy cattle farms, income, family of farmers 


\section{PENDAHULUAN}

Kecamatan Musuk merupakan Kecamatan yang memiliki populasi ternak sapi perah yang cukup banyak dibandingkan dengan kecamatan-kecamatan yang berada wilayah di Kabupaten Boyolali. Kecamatan Musuk menyumbang populasi ternak sapi perah sebesar 19.812 ekor atau sekitar $31,70 \%$ dari jumlah sapi yang ada di Kabupaten Boyolali yang memiliki populasi ternak sapi perah sebesar 62.484 (Badan Pusat Statistik Boyolali, 2011). Mukhtar (2006) menjelaskan bahwa, peternakan sapi perah rakyat merupakan suatu kegiatan usaha tingkat keluarga yang bersifat statis, dengan skala usaha yang kecil dan tanpa sepenuhnya mengikuti prinsip-prinsip ekonomi. Jenis usaha peternakan rakyat sering disebut pula sebagai usaha ternak tradisional yang masih memerlukan pembinaan, pengembangan dan pengawasan dari pemerintah.

Menurut Tawaf et al. (2006), secara finansial pendapatan yang diperoleh mampu memberikan imbalan terhadap tenaga kerja petani, menutup biaya oportunitas dari bunga pinjaman dan mampu memberikan imbalan terhadap tenaga kerja peternak yang dicurahkan untuk memelihara ternak dan mengelola usahanya. Menurut Soekartawi (1993), pendapatan usaha sapi perah dapat diketahui melalui analisis pendapatan, untuk mengetahui jumlah pendapatan tersebut perlu dicermati antara biaya-biaya yang diperhitungkan dan biaya yang tidak diperhitungkan.

Pengelolaan dan pemeliharaan sapi perah dapat dijadikan sebagai salah satu cara untuk meningkatkan pendapatan rumah tangga. Penelitian ini bertujuan untuk mengetahui tentang karakteristik dan tatalaksana usaha peternakan sapi perah, menganalisis besarnya kontribusi usaha ternak sapi perah terhadap pendapatan keluarga peternak, menganalisis hubungan antara skala usaha dengan pendapatan dan kontribusi pendapatan usaha ternak sapi perah, serta menganalisis pengaruh berbagai faktor produksi terhadap tingkat pendapatan peternak di Kecamatan Musuk Kabupaten Boyolali.

\section{METODE PENELITIAN}

Penelitian ini telah dilaksanakan pada Bulan Juli 2013 di tiga Desa di Kecamatan Musuk Kabupaten Boyolali yaitu Desa Ringin larik, Desa Kebon gulo, dan Desa Dragan. Pelaksanaan penelitian menggunakan metode survei (survey method) terhadap 60 peternak sapi perah di Kecamatan Musuk, yang dipilih secara sengaja (Purposive Sampling) dengan pertimbangan waktu, kemampuan, dan jangkauan peneliti. Penelitian survei merupakan penelitian yang mengambil sampel dari satu populasi dan menggunakan kuesioner sebagai alat pengumpulan data yang pokok (Singarimbun, 1995). Teknik pengambilan data dalam penelitian ini menggunakan teknik Rapid Rural Appraisal (RRA). Data primer diperoleh melalui wawancara langsung dengan responden. Data sekunder diperoleh dari berbagai instansi yang terkait.

Hasil penelitian ini dianalisis deskriptif kuantitatif (quantitative descriptive analysis) terhadap data yang diperoleh dari pertanyaan yang diajukan terhadap responden. Sugiyono (2003) menjelaskan bahwa penelitian deskriptif kuantitatif merupakan pengumpulan data yang diperoleh dari sampel populasi penelitian dianalisis sesuai dengan metode statistik yang digunakan kemudian diinterprestasikan. Analisis penelitian meliputi analisis pendapatan usaha ternak sapi perah, analisis pendapatan keluarga peternak, analisis kontribusi usaha ternak sapi perah terhadap pendapatan keluarga peternak di Kecamatan Musuk Kabupaten Boyolali, analisis Kolerasi Pearson dan Regresi Linier Berganda.

\section{HASIL DAN PEMBAHASAN}

\section{Karakteristik responden}

Karakteristik peternak menggambarkan tentang keadaan dari peternak dari segi 
Tabel 1. Karakteristik responden di Kecamatan Musuk

\begin{tabular}{|c|c|c|}
\hline Karakteristik & Responden (orang) & Persentase $(\%)$ \\
\hline \multicolumn{3}{|l|}{ Umur (tahun) } \\
\hline$<20$ tahun & 0 & 0,00 \\
\hline 20-40 tahun & 5 & 8,33 \\
\hline 41-60 tahun & 40 & 66,60 \\
\hline$>60$ tahun & 15 & 75,00 \\
\hline Jumlah & 60 & 100 \\
\hline \multicolumn{3}{|l|}{ Tingkat pendidikan } \\
\hline $\mathrm{SD} /$ sederajat & 41 & 68,34 \\
\hline $\mathrm{SMP} /$ sederajat & 8 & 13,33 \\
\hline SMA/sederajat & 8 & 13,33 \\
\hline S1/Diploma & 3 & 5,00 \\
\hline Jumlah & 60 & 100 \\
\hline \multicolumn{3}{|l|}{ Pengalaman beternak } \\
\hline 1-10 tahun & 5 & 8,33 \\
\hline 11-20 tahun & 6 & 10,00 \\
\hline$>21$ tahun & 49 & 81,67 \\
\hline Jumlah & 60 & 100 \\
\hline \multicolumn{3}{|l|}{ Pekerjaan utama } \\
\hline PNS & 3 & 5,00 \\
\hline Wiraswasta & 1 & 1,67 \\
\hline Pensiunan & 1 & 1,67 \\
\hline Petani & 46 & 76,66 \\
\hline Buruh & 2 & 3,33 \\
\hline Tukang & 7 & 11,67 \\
\hline Jumlah & 60 & 100 \\
\hline
\end{tabular}

Sumber : Data primer terolah 2013.

umur, pendidikan, pengalaman beternak dan pekerjaan utama peternak di Kecamatan Musuk. Karakteristik responden di Kecamatan Musuk dapat dilihat pada Tabel 1. Menurut Arsyad (1999), umur produktif adalah umur antara 15 tahun sampai dengan 64 tahun. Hasil penelitian menunjukkan bahwa $66,67 \%$ peternak berumur antara 40 sampai 60 tahun dan $8,33 \%$ pada umur 20 sampai 40 tahun. Terdapat 45 orang atau $75 \%$ peternak termasuk dalam kategori produktif. Dalam hal ini berarti sebagian besar peternak di Kecamatan Musuk Kabupaten Boyolali tergolong dalam umur produktif sehinggga masih dapat ditingkatkan pengetahuan dan keterampilan dengan cara memberi inovasi baru dibidang peternakan.

Tingkat pendidikan formal yang pernah ditempuh tingkat pendidikan responden terbanyak hanya tamat SD yang berjumlah 41 orang atau $68,34 \%$. Tingkat pendidikan responden di kecamatan musuk bisa dikatan masih rendah, hal ini dikarenakan lebih dari setengah jumlah responden hanya tamat SD. Peternak yang memiliki tingkat pendidikan lebih tinggi seharusnya dapat meningkatkan pendapatannya namun tidak demikian dilapangan yang pada umumnya peternak tergolong berpendidikan rendah.

Pengalaman beternak peternak paling banyak adalah selama lebih dari 21 tahun. Peternak sudah cukup lama dalam mengembangkan usaha sapi perah. Pengalaman beternak yang dimiliki akan menjadikan peternak lebih mandiri dan terampil dalam pengelolaan usaha ternaknya sehingga dapat meningkatkan usaha dan pendapatannya. 
Tabel 2. Pendapatan usaha ternak sapi perah skala usaha 4 ekor $(n=60)$

\begin{tabular}{lrr}
\multicolumn{1}{c}{ Keterangan } & \multicolumn{1}{c}{$\begin{array}{c}\text { Jumlah total } \\
(\mathrm{Rp} / \text { tahun })\end{array}$} & $\begin{array}{r}\text { Jumlah rata rata } \\
\text { (Rp/peternak/tahun) }\end{array}$ \\
\hline (A) Penerimaan Usaha Ternak & & \\
1) Produksi susu & $966.900 .000,00$ & $3.379 .167,00$ \\
2) Penjualan pedet & $202.750 .000,00$ & $16.115 .000,00$ \\
$\quad$ Total (A) & $1.169 .650 .000,00$ & $19.494 .167,00$ \\
(B) Biaya Variabel & & \\
1) Biaya pakan & $471.762 .500,00$ & $7.862 .708,33$ \\
2) Biaya tenaga kerja & $239.850 .000,00$ & $3.997 .500,00$ \\
3) Biaya obat & $2.480 .000,00$ & $41.333,00$ \\
4) Biaya IB & $8.340 .000,00$ & $139.000,00$ \\
$\quad$ Total (B) & $722.432 .500,00$ & $12.040 .542,33$ \\
\hline (C) Margin Kotor (A-B) & $447.217 .500,00$ & 7.453 .625 .33 \\
(D) Biaya Tetap & & $141.617,00$ \\
1) Penyusutan peralatan & $8.497 .000,00$ & $143.958,00$ \\
2) Penyusutan kandang & $8.637 .500,00$ & $685.000,00$ \\
3) Penyusutan ternak & $41.100 .000,00$ & $970.575,00$ \\
\hline Total (D) & $58.234 .500,00$ & $6.483 .050,33$ \\
\hline (E) Pendapatan Usaha Ternak Sapi & $388.983 .000,00$ & \\
perah (C-D) &
\end{tabular}

Sumber : Data primer terolah 2013

Mata pencaharian utama yang dilakukan oleh responden bermacam macam yaitu sebagai petani, buruh, Pensiunan, PNS, Wiraswasta dan tukang. Petani merupakan mata pencaharian yang paling banyak ditekuni oleh responden yaitu sebesar 76,67\%. Topografi Kecamatan Musuk merupakan wilayah pegunungan, sehingga cocok untuk usaha pertanian. Keterampilan bercocok tanam merupakan turun-temurun dari orang tua, sehingga sebagian besar responden bermata pencaharian sebagai petani.

\section{Pendapatan Usaha Ternak Sapi Perah}

Hasil pendapatan responden dari usaha ternak sapi perah di Kecamatan Musuk Kabupaten Boyolali dapat dilihat pada Tabel 2. Hasil pendapatan usaha ternak sapi perah pada daerah penelitian di dapat dari penjualan susu dan ternak. Pendapatan rata rata responden peternak sapi perah adalah Rp 6.483.050,33. Pendapatan usaha ternak sapi perah ini lebih besar dibandingkan pada penelitian Wahyuningrum (2011), yang menunjukkan pendapatan rata rata respondennya hanya Rp 3.184.332,04. Pada dasarnya usaha peternakan di daerah penelitian yang masih bersifat tradisional sehingga pendapatan usaha peternakan sapi perah masih dikatakan rendah. Skala kepemilikan ternak yang rendah mempengaruhi rendahnya tingkat pendapatan peternak.

\section{Pendapatan Usaha Pertanian}

Rata rata pendapatan responden dari hasil komoditas pertanian yaitu sebesar $\mathrm{Rp}$. 22.368.033,00/tahun. Pada daerah penelitian sistem pertanianya adalah Tumpang sari (Cabai, Tembakau, singkong, pepaya dan Jagung). Tidak semua petani mempunyai pohon cengkeh dan pohon cengkeh tidak ditanam secara khusus akan tetapi hanya ditanam di pekarangan rumah. Jumlah petani cengkeh hanya 12 orang, tetapi rata-rata pendadapatan petani paling tinggi dikarenakan harga cengkeh yang mahal. Satu Kg cengkeh dapat dihargai Rp. 120.000,00. Pendapatan rata-rata terkecil petani dari usaha pepaya yaitu sebesar Rp. 
Tabel 3. Hasil pendapatan dari komoditi usaha pertanian $(n=60)$

\begin{tabular}{lcrrr}
\hline $\begin{array}{l}\text { Jenis usaha } \\
\text { pertanian }\end{array}$ & $\begin{array}{c}\text { Jumlah } \\
\text { petani }\end{array}$ & $\begin{array}{c}\text { Pendapatan total } \\
\text { responden }(\mathrm{Rp} / \mathrm{th})\end{array}$ & $\begin{array}{c}\text { Pendapatan rata } \\
\text { rata petani } \\
(\mathrm{Rp} / \mathrm{th})\end{array}$ & $\begin{array}{c}\text { Pendapatan rata rata } \\
\text { tiap reponden } \\
(\mathrm{Rp} / \mathrm{th})\end{array}$ \\
\hline Cabai & 58 & $654.500 .000,00$ & $11.284 .483,00$ & $10.908 .333,00$ \\
Tembakau & 52 & $115.600 .000,00$ & 2.223 .076 .90 & $1.926 .667,00$ \\
Pepaya & 47 & $61.232 .000,00$ & $1.302 .808,50$ & $1.020 .533,00$ \\
singkong & 58 & $93.600 .000,00$ & $1.613 .793,00$ & $1.560 .000,00$ \\
Cengkeh & 12 & $143.400 .000,00$ & $11.950 .000,00$ & $2.390 .000,00$ \\
Jagung & 54 & $273.750 .000,00$ & 5.069 .444 .40 & $4.562 .500,00$ \\
$\quad$ Jumlah & & $1.342 .082 .033,00$ & $33.443 .605,80$ & $22.368 .033,00$ \\
\hline
\end{tabular}

Sumber : Data Primer terolah 2013

Tabel 4. Hasil pendapatan non pertanian $(n=60)$

\begin{tabular}{lcc}
\hline Pekerjaan & Jumlah & Pendapatan total responden $(\mathrm{Rp} / \mathrm{th})$ \\
\hline PNS & 3 & $70.800 .000,00$ \\
Wiraswasta & 1 & $72.000 .000,00$ \\
Pensiunan & 1 & $13.200 .000,00$ \\
Buruh & 2 & $28.800 .000,00$ \\
Tukang & 7 & $91.200 .000,00$ \\
Jumlah & 14 & $276.000 .000,00$
\end{tabular}

Sumber : Data primer terolah 2013

1.302.808,50 dikarenakan tanaman pepaya merupakan hasil sampingan yang dikelola di ladang.

Berdasarkan Tabel 3 diatas pendapatan pertanian cukup menyumbang banyak dari pendapatan keluarga, hal ini dikarenakan sebagian besar penduduknya mempunyai lahan petanian dan komoditas pertanian merupakan mata pencaharian pokok. Kecamatan Musuk merupakan wilayah yang potensial untuk komoditi pertanian, karena letak geografis yang berada pada kaki Gunung Merapi dan kondisi tanah yang subur.

\section{Pendapatan Usaha Non Pertanian}

Seperti terlihat dalam Tabel 4 bahwa usaha non pertanian dari responden yang jumlah pekerjaan yang paling banyak dan pendapatannya paling besar adalah tukang. Pendapatan terbesar yaitu Rp 91.200.000,00/ tahun dari usaha lainnya.

Tingkat pendidikan responden yang rendah memungkinkan responden bekerja hanya sebagai tukang. Sumber pendapatan usaha non pertanian hanya menyumbang sebagian kecil dari pendapatan keluarga peternak.Pendapatan non pertanian yang paling sedikit adalah dari pensiunan PNS yaitu sebesar Rp. 13.200.000,00/tahun.

\section{Kontribusi Usaha Ternak Sapi Perah Terhadap Pendapatan Keluarga Peternak}

Besarnya kontribusi pendapatan usaha ternak sapi perah terhadap pendapatan keluarga petani peternak setiap skala dapat dilihat pada Tabel 5. Kontribusi pendapatan usaha ternak sapi perah terhadap pendapatan peternak di kecamatan musuk sebesar 19,38\%. Menurut Saragih (2001), menjelaskan bahwa usaha ternak sapi perah pada daearah penelitian termasuk ke dalam tipologi usaha sambilan, hal ini dikarenakan kontribusinya terhadap pendapatan keluarga peternak kurang dari $30 \%$.

\section{Analisis kolerasi pearson}

Hasil analisis Korelasi Pearson dapat dilihat pada Tabel 6. Nilai korelasi antara skala usaha ternak sapi perah dengan 
Tabel 5. Kontribusi Usaha Ternak Sapi Perah Terhadap pendapatan $(\mathrm{n}=60)$

\begin{tabular}{lrrr}
\hline Jenis Penerimaan & $\begin{array}{c}\text { Pendapatan total } \\
\text { responden }(\mathrm{Rp} / \mathrm{th})\end{array}$ & $\begin{array}{r}\text { Pendapatan rata rata } \\
\text { tiap reponden }(\mathrm{Rp} / \mathrm{th})\end{array}$ & $\begin{array}{c}\text { Kontribusi } \\
(\%)\end{array}$ \\
\hline Usaha ternak sapi perah & $388.983 .000,00$ & $6.483 .050,00$ & 19,38 \\
Usaha pertanian & $1.342 .082 .033,00$ & $22.368 .033,33$ & 66,87 \\
Usaha non pertanian & $276.000 .000,00$ & $4.600 .000,00$ & 13,75 \\
$\quad$ Jumlah & $2.007 .065 .033,00$ & $33.451 .083,33$ & 100 \\
\hline
\end{tabular}

Sumber: Data primer terolah 2013.

pendapatan usaha ternak Sapi Perah dan nilai korelasi antara skala usaha ternak Sapi Perah dengan persentase kontribusi pendapatan usaha ternak sapi perah memiliki nilai yang positif yaitu 0,597 dan 0,521 . Nilai kolerasi yang positif, maka perubahan pada salah satu variabel akan diikuti perubahan variabel yang lain dengan arah yang sama dan hubungan yang semakin kuat. Semakin besar skala usaha ternak sapi perah akan membuat tingkat pendapatan peternak dan kontribusi pendapatan usaha ternak sapi perah semakin tinggi.

\section{Analisis regresi linier berganda}

Hasil analisis data dengan menggunakan program SPSS 16, diperoleh hasil seperti pada Tabel 7 sebagai berikut:

Analisis regresi dalam Tabel 7 diatas menghasilkan persamaan regresi linier berganda sebagai berikut:

$$
\begin{gathered}
Y=-1,570-1,349 \times 1+3,186 \times 2+4,085 \\
X 3+33,525 X 4+23,039 \times 5
\end{gathered}
$$

Keterangan: $\hat{Y}=$ Tingkat pendapatan peternak (Y) dipengaruhi berbagai faktor produksi dalam memelihara sapi perah; $\mathrm{a}=$ Koefisien intercept (konstanta); $\mathrm{X}_{1}=$ Biaya Pakan Konsentrat; $\mathrm{X}_{2}=$ Biaya Pakan Hijauan; $X_{3}=$ Biaya Tenaga kerja; $\mathrm{X}_{4}=$ Biaya Obat-obatan $\mathrm{X}_{5}=$ Biaya IB

Hasil persamaan regresi tersebut nilai konstanta sebesar -1,570. Sesuai pendapat Algifari (2003), pengujian terhadap variasi perubahan nilai variabel dependen $(\mathrm{Y})$ yang dapat dijelaskan oleh variasi perubahan nilai variabel independen $\left(\mathrm{X}_{1}, \mathrm{X}_{2}, \mathrm{X}_{3}, \mathrm{X}_{4}, \mathrm{X}_{5}\right)$ dapat dibuktikan bahwa semua variabel independen secara bersama-sama (secara stimulan) dapat mempengaruhi variabel dependen.

Koefisien determinasi $\left(\mathrm{R}^{2}\right)$ berguna untuk mengukur tingkat ketepatan (goodness of fit) yang merupakan porporsi atau persentase sumbangan $X$ terhadap variasi naik turunnya $Y$. Hasil analisis regresi diperoleh nilai koefisien determinasi $\left(\mathrm{R}^{2}\right)$ sebesar 0,474 . Ini berarti besarnya semua variabel bebas mempengaruhi variabel terikat terhadap pendapatan sebesar $47,4 \%$ sedangkan sisanya sebesar 52,6\% dipengaruhi oleh variabel lain diluar variabel yang diteliti atau dimasukkan dalam kesalahan pengganggu.

Uji F merupakan alat yang digunakan untuk menguji apakah variabel independen berpengaruh secara bersamaan terhadap variabel dependen. Hasil analisis dengan taraf $\alpha=0,05$ nilai $F_{\text {hitung }}$ lebih besar dari $F_{\text {tabel }}(9,719>2,557)$. Berdasarkan perhitungan data dapat diambil kesimpulan bahwa variabel independen (biaya pakan konsentrat, biaya pakan hijauan, biaya obatobatan, biaya IB, dan biaya tenaga kerja) berpengaruh secara bersama-sama terhadap variabel dependen (pendapatan).

Tingkat signifikasi dari masingmasing koefisien diuji dengan menggunakan uji parsial t-test tampak pada tabel 7. Nilai variabel biaya pakan konsentrat $\left(\mathrm{X}_{1}\right)$, pakan hijauan $\left(\mathrm{X}_{2}\right)$ dan biaya Obat $\left(\mathrm{X}_{4}\right)$ lebih kecil dibandingkan dengan nilai $t_{\text {tabel }}$ atau dapat diartikan bahwa variabel biaya pakan konsentra, hijauan dan obat obatan tidak berpengaruh terhadap pendapatan (Y). Biaya pakan konsentrat $\left(\mathrm{X}_{1}\right)$ tidak signifikan, disebabkan karena pakan konsentrat diberikan tidak sesuai kebutuhan ternak dan berdasarkan jumlah kepemilikan ternak. 
Tabel 6. Nilai korelasi Pearson antara skala usaha peternakan sapi perah, pendapatan usaha ternak sapi perah dan kontribusi pendapatan usaha ternak sapi perah

\begin{tabular}{lcc}
\hline \multicolumn{1}{c}{ Variabel } & Korelasi Pearson & Sig. (2-tailed) \\
\hline SK Sapi perah - Pendapatan & $0,597^{* *}$ & 0,000 \\
SK Sapi perah - Kontribusi & $0,521^{* *}$ & 0,000 \\
Pendapatan - Kontribusi & $0,753^{* *}$ & 0,000 \\
\hline
\end{tabular}

Keterangan :

** : Korelasi signifikan pada taraf kepercayaan 99\% (2-tailed)

SK Sapi perah : Skala Kepemilikan Sapi Perah

Sumber: Data primer terolah 2013.

Tabel 7. Hasil Analisis Regresi Berganda

\begin{tabular}{lccl}
\hline Variabel & Koefisien Regresi & t hitung & Sig \\
\hline $\mathrm{X}_{1}$ (Pakan konsentrat) & $-1,349$ & $-0,833^{*}$ & 0,408 \\
$\mathrm{X}_{2}$ (Pakan hijauan) & 3,186 & $1,225^{*}$ & 0,226 \\
$\mathrm{X}_{3}$ (Tenaga kerja) & 4,085 & $2,081^{* *}$ & 0,042 \\
$\mathrm{X}_{4}$ (Obat-obatan) & 33,525 & $0,694^{*}$ & 0,490 \\
$\mathrm{X}_{5}$ (IB) & 23,039 & $2,066^{* *}$ & 0,044 \\
Konstata & $-1,570$ & & \\
$\mathrm{~F}$ hitung & 9,719 & & \\
Adjust $\mathrm{R}^{2}$ & 0,425 & \\
$\mathrm{R}$ Square $\left(\mathrm{R}^{2}\right)$ & 0,474 & & \\
$\mathrm{R}$ & $0,688^{(a)}$ & & \\
Variabel terikat $=\mathrm{Y}$ (Pendapatan) & & \\
Keterangan : & & \\
* : Tidak signifikan & & & \\
** : Signifikan & & \\
Sumber: Data primer terolah 2013 & & &
\end{tabular}

Biaya pakan hijauan $\left(\mathrm{X}_{2}\right)$ tidak signifikan, disebabkan karena pembelian pakan hijauan hanya pada saat musim kering atau pada saat ketersediaan pakan hijauan berkurang. Pola pemeliharaan ternak sapi perah pada daerah penelitian masih bersifat tradisional dikarenakan pemberian pakan yang seadanya dan tidak sepenuhnya mengikuti prinsip-prinsip manajemen pemeliharaan ternak sapi perah. Biaya obat $\left(\mathrm{X}_{4}\right)$ tidak signifikan, disebabkan karena dalam penelitian ini tidak didapatkan masalah penyakit yang serius yang menyerang ternak sapi perah karena apabila ada ternak sakit peternak memberikan pengobatan secara tradisional.

Hasil koefisien $t_{\text {hitung }}$ variabel biaya Tenaga kerja $\left(\mathrm{X}_{3}\right)$ dan biaya IB $\left(\mathrm{X}_{5}\right)$ mempunyai nilai $t_{\text {hitung masing masing } 2,081}$ dan 2,066. Dibandingkan dengan nilai $t_{\text {tabel }}$ lebih kecil dari pada $t_{\text {hitung. Hasil pengujian }}$ menunjukan variabel biaya obat-obatan dan biaya IB berpengaruh terhadap pendapatan. Biaya tenaga kerja $\left(\mathrm{X}_{3}\right)$ signifikan dikarenakan biaya yang dikeluarkan untuk tenaga kerja skala usaha 4 ekor atau lebih adalah sama. Variabel biaya IB $\left(\mathrm{X}_{5}\right)$ signifikan dikarenakan tingkat keberhasilan IB pada ternak rendah. Rata rata ternak baru bunting setelah dua kali di inseminasi buatan.

\section{KESIMPULAN}

Berdasarkan hasil penelitian skala usaha peternakan sapi perah di Kecamatan Musuk rata rata adalah 4 ekor. Rata-rata pendapatan bersih usaha peternakan sapi perah di Kecamatan Musuk sebesar Rp. 6.483.050,33/tahun. Kontribusi usaha peternakan sapi perah terhadap pendapatan keluarga peternak di Kecamatan Musuk 
hanya sebesar 19,38\% atau termasuk ke dalam tipologi usaha sambilan. Hasil analisis kolerasi antara skala usaha ternak sapi perah dengan pendapatan dan kontribusi pendapatan usaha ternak sapi perah memiliki nilai yang positif yaitu memiliki hubungan yang kuat dan linear, semakin besar skala usaha ternak sapi perah akan membuat tingkat pendapatan peternak dan kontribusi pendapatan usaha ternak sapi perah semakin tinggi. Hasil analisis regresi linier berganda menunjukkan bahwa faktor biaya Tenaga kerja dan biaya IB berpengaruh terhadap pendapatan peternak sapi perah.

\section{DAFTAR PUSTAKA}

Algifari. 2003. Statistika induktif untuk ekonomi dan bisnis. Edisi II. Akademi manajemen perusahaan YKPN. Yogyakarta.

Arsyad, L. 1999. Ekonomi pembangunan. Edisi ke 4. Universitas Gadjah mada. Yogyakarta.

Badan Pusat Statistik Boyolali. 2011. Kecamatan Musuk dalam Angka 2011. BPS. Boyolali

Mukhtar, A. 2006. Ilmu produksi ternak perah. UNS Press. Surakarta.

Saragih, B. 2001. Kumpulan pemikiran agribisnis berbasis peternakan. pusat studi pembangunan dan lembaga penelitian. Institut Pertanian Bogor. Bogor.

Singarimbun, M. 1995. Metode penelitian survei. LP3ES. Jakarta.

Soekartawi. 1993. Agribisnis teori dan aplikasinya. PT Grafindo. Jakarta.

Sugiyono. 2003. Metode penelitian bisnis. Pusat Bahasa Depdiknas. Bandung.

Tawaf, R., Firman, A., dan Sugandi, D. 2006.Analisiskinerja usaha ternak sapi perah rakyat pada tiga kondisi usaha koperasi/KUD susu di Kabupaten Bandung. Bahan seminar kinerja usaha peternakan sapi perah di Jawa Barat. Badan Penelitian dan Pengembangan Pertanian.

Wahyuningrum, R.F. 2011. Analisis pendapatan usaha peternakan sapi perah rakyat di Kecamatan Musuk Kabupaten Boyolali. Skripsi. Jurusan Peternakan Fakultas Pertanian. Universitas Sebelas. 